\title{
Psychology and Human Factors Engineering and Its Application in the User-centered Design
}

\author{
Dinglin Tu \\ Shenzhen Experimental School, Guangdong, Shenzhen, China \\ 1308252962@qq.com
}

Keywords: Psychology; Human factors engineering; User-centered; Process design and application

\begin{abstract}
The application of psychology and human factors engineering in user-centered design can improve the environment of man-machine interaction and the work efficiency. The paper first briefly introduced the human factors engineering and related psychological contents, and then discussed the application of psychology and human factors engineering in human-oriented design. Based on the case of company J's actual production, the paper optimized its man-machine operating environment and process and evaluated the new optimization outcome of the new man-machine plan.
\end{abstract}

\section{Introduction}

Human factors engineering is one of the most important topics in the field of industrial research. Based on the related theories of physiology and psychology, the interaction between human and machine as well as human and environment have been widely explored, along with specific focuses on human health, operational comfort, safety and work efficiency, followed with the optimization for the design of the onsite production process. The existing research results and the actual situation in industrial engineering revealed that the user-centered engineering design based on human factors engineering can realize the efficient integration of personnel and equipment and improve the industrial production efficiency.

\section{Brief Introduction to Human Factors Engineering}

Human factors engineering is a comprehensive subject that studies the influencing factors of human beings. The research object and the scope of its application are mainly workers, equipment and environment in industrial engineering. Human factors engineering covers a wide range of disciplines, including psychology, physiology, human health, labor hygiene and environmental engineering as well as others, remaining as a comprehensive and applied research discipline. Starting from the characteristics of human behavior, the human factor engineering involves the production tools and environment suitable for the operators and explores operators' physical and psychological needs in the work environment as well as the factors influencing the work efficiency to solve the environmental adaptability issue of workers and improve the safety, comfort and coordination in the production process, thereby elevating the productivity [1].

\section{Human-oriented Design Process and Application Based on Psychology and Human Factors Engineering}

\subsection{Company J's situation}

Company $\mathrm{J}$ was founded in 2008 and its key business is the production of automotive lead-acid battery and other high-performance power battery. The company has equipped with advanced production equipment and technology and the annual capacity could reach 8 million with the 
estimated sales revenue to be 4 billion yuan. The featured product of $\mathrm{J}$ is the automotive maintenance-free lead-acid battery whose composition and functions are shown in Table 1 [2].

Table 1 Product features of automotive maintenance-free lead-acid battery

\begin{tabular}{|c|l|}
\hline Product name & \multicolumn{1}{|c|}{ Automotive maintenance-free lead-acid battery } \\
\hline Composition & $\begin{array}{l}\text { Mainly consisting of positive and negative plates, battery jar, septum belt, } \\
\text { electrolyte, electric eye and post adapter }\end{array}$ \\
\hline Product features & $\begin{array}{l}\text { Small amount of water decomposition during charging; plastic battery jar; tight } \\
\text { sealing; little environmental pollution; no corrosion caused to the post adaptor } \\
\text { and car body }\end{array}$ \\
\hline Working principles & $\begin{array}{l}\text { Adopting the electrochemical principle. The positive electrode of the battery is } \\
\text { a lead dioxide active material and the negative electrode is a sponge lead active } \\
\text { material. Both of them can generate a voltage of about 2.1V in the sulfuric acid } \\
\text { electrolyte }\end{array}$ \\
\hline Major functions & $\begin{array}{l}\text { (1) powering the electrical equipment like the starter when the engine is } \\
\text { started; } \\
\text { engine is operating at low speed or outage; } \\
\text { (3) when the power generation system of the automotive electrical equipment } \\
\text { is in the output state, powering your automotive electrical equipment for a } \\
\text { limited time }\end{array}$ \\
\hline
\end{tabular}

Based on the structural features and functional characteristics of the products in Table 1, Company J's manufacturing process of the lead-acid battery product can be divided into eight steps, including the manufacturing of lead tape, the manufacturing of lead powder and the production of positive and negative plates and others. For this production process, the production site could be divided into several areas to arrange the equipment. The entire production area is divided into three regions, MP, GGA and FOR, and the specific arrangement is shown in Table 2.

Table 2 Overall arrangement of production area

\begin{tabular}{|c|c|c|}
\hline Main production areas & $\begin{array}{l}\text { Production areas and } \\
\text { production lines }\end{array}$ & Attribute of the area \\
\hline MP & $\begin{array}{c}\text { OXID area, Pasting } \\
\text { production line, NGP } \\
\text { production line, PTP } \\
\text { production line }\end{array}$ & Basic production area \\
\hline GGA & $\begin{array}{l}\text { Including } 6 \text { production } \\
\text { lines and } 8 \text { envelopes }\end{array}$ & Main production area \\
\hline FOR & $\begin{array}{c}\text { OCV area, FOR-ASMB } \\
\text { area }\end{array}$ & Finish area \\
\hline
\end{tabular}

According to Company J's production capacity of 6 production lines in major production areas, it is planned to optimize the design of its production process. Based on psychology and human factors engineering, the machinery and equipment are expected to be rationally arranged to improve the production capacity.

\subsection{Man-machine operation optimization design}

According to the current arrangement in the GGA, every station of \#4 production line is seated by a production worker. Overall speaking, the team is somehow oversized. Especially in the post height measurement area, the flow line operating space is quite narrow and two workers assigned here might disturb each other during the operation. In the production line, the main function of the buffer machine is to avoid the failure of the envelope machine and to provide spare feeding for subsequent 
production, but at present it only plays a buffering role. There are still many unreasonable designs in the man-machine arrangements throughout the production area, which needs to be further optimized.

From the perspective of psychology and human factors engineering, we adopt the Fifty/Fifty Law and ECRSI Principles to optimize the production process of Company J's GGA area. Through the qualitative analysis of the production process, the necessary operation steps and production flows were confirmed in the production line and the production processes were simplified. Table 3 shows the process flow before and after simplification.

Table 3 Production process before and after simplification

\begin{tabular}{cccc}
\hline & $\begin{array}{c}\text { Process station } \\
\text { steps }\end{array}$ & Inspection station & $\begin{array}{c}\text { Combined process } \\
\text { and inspection } \\
\text { station }\end{array}$ \\
\hline $\begin{array}{c}\text { Before } \\
\text { simplification }\end{array}$ & 21 & 8 & 0 \\
After simplification & 19 & 3 & 5 \\
\hline
\end{tabular}

On this basis, the work measurement was carried out and its purpose mainly includes three aspects: (1) as the basis for the workshop production and operating system design to analyze labor formula; (2) to improve on-site operation process; (3) to offer reference for the work evaluation. Based on the above objectives, the direct test method was used for the work measurement with the electronic timer applied to count the time that the operator spent on the operation, which was compared to the standard time estimation parameters to determine the reasonable time needed by the operators to complete the operation. After completing the on-site work measurement, the data obtained were processed and calculated with the outliers excluded. Finally, the work evaluation was arranged by using the leveling method to determine the rating and evaluation coefficient. The evaluation coefficient calculation formula is: evaluation coefficient $=1+$ skill coefficient + work efficiency coefficient + working condition coefficient + consistency coefficient.

After the measurement and analysis, the man-machine operation flow is planned to be optimized. The main optimization design includes: (1) Optimizing the operation procedure of ENC. Since the Buffer machine does not play a practical role in the whole process and it consumes a lot of working time, it was decided that the buffer device shall be removed. The operation cycle can be reduced from 250s to 190s without affecting the original operation flow, and the operator utilization rate would increase from $67.20 \%$ to $85.26 \%$; (2) The next optimization design was for the battery jar welding process to solve the problem of idle personnel during the machine drilling and expansion. The exact improvement measures are to arrange the operators to add flux and lead ingots during drilling and expanding equipment. After the optimization design, the operating cycle can be reduced from the previous 206s to $174 \mathrm{~s}$, so that the utilization rate of the operator would be increased from $46.12 \%$ to $54.60 \%$. (3) The HTP process was then optimized to solve the problem of idle personnel. When the operator gives the battery the electric eye, they could use the machine to measure the height of the post.

\subsection{Evaluation of the new man-machine plan}

After the adjustment based on the optimization plans above, the effectiveness of each station and the entire production process have been significantly improved. Table 4 shows the improvement effect of each station. Table 5 shows the effect of improving the body production process in the GGA production area. 
Table 4 Optimization effect of each station

\begin{tabular}{ccccc}
\hline Equipment & \multicolumn{2}{c}{ Before optimization } & \multicolumn{2}{c}{ After optimization } \\
station & Operator & Machine & Operator & Machine \\
\hline ENC & $67.20 \%$ & $92.00 \%$ & $85.26 \%$ & $92.63 \%$ \\
Battery bar & $46.12 \%$ & $53.88 \%$ & $54.60 \%$ & $63.79 \%$ \\
welding & $32.65 \%$ & $67.35 \%$ & $37.50 \%$ & $77.34 \%$ \\
HTP & &
\end{tabular}

Table 5 Optimization effect of production process in the production area

\begin{tabular}{ccc}
\hline Category & Before optimization & After optimization \\
\hline Production cycle & $603 \mathrm{~s}$ & $492 \mathrm{~s}$ \\
Number of operators & 11 & 8 \\
& & 11 \\
Number of equipment & 12 & $59.12 \%$ \\
Personnel utilization rate & $48.65 \%$ & $77.92 \%$ \\
Machine utilization rate & $71.07 \%$ & \\
\hline
\end{tabular}

It can be seen from Table 4 and Table 5 that after optimization, the overall production efficiency of stations and production areas has been significantly improved, reducing the production cycle from 603s to 492s.

\section{Conclusion}

In summary, the optimization design based on psychology and human factors engineering for industrial engineering production process can effectively improve the industrial production conditions as well as machine and personnel utilization rate. Through the operation of the production area determination, that is, the production process of time-consuming measurement analysis, the unnecessary time-consuming could be avoided, thereby enhancing the production efficiency and economic profit.

\section{References}

[1] Wilpert B. Psychology and human factors engineering [J]. Cognition Technology \& Work, 2008, 10(1):15-21.

[2] Eccles D W, Ward P, Woodman T, et al. Where's the emotion? How sport psychology can inform research on emotion in human factors [J]. Human Factors, 2011, 53(2):180-202.

[3] Zeng L, Proctor R W, Salvendy G. Fostering creativity in product and service development: validation in the domain of information technology [J]. Human Factors, 2011, 53(3):245-70.

[4] I.A.R. GALER. The Role of Psychology in the Design and Evaluation of Transport Systems [J]. Ergonomics, 1979, 22(2):129-133.

[5] Re A, Macchi L. From cognitive reliability to competence? An evolving approach to human factors and safety [J]. Cognition Technology \& Work, 2010, 12(2):79-85.

[6] Mahlmeister L R. Human factors and error in perinatal care: the interplay between nurses, machines, and the work environment [J]. Journal of Perinatal \& Neonatal Nursing, 2010, 24(1):12. 